\title{
Targeting Lung Inflammation in Cystic Fibrosis
}

\section{Rafat Siddiqui*}

Cellular Biochemistry Laboratory, Methodist Research Institute, Indiana University Health, Indiana University School of Medicine, Indianapolis, IN 46202, USA

Cystic fibrosis $(\mathrm{CF})$ is an autosomal recessive disease found mostly in the Caucasian population; a major complication of CF that often leads to mortality is lung inflammation. Playing a key role in the inflammation, as demonstrated by several studies, is the continuous recruitment of neutrophils to the lung [1-3]. Despite these millions of activated neutrophils, CF patients cannot adequately defend against invading pathogens because the bactericidal activity of the neutrophils in CF patients is dysregulated [4,5] due to mutations in the cystic fibrosis transmembrane conductance regulator (CFTR) gene [6]. When pathogens such as Staphylococcus aureus, Pseudomonas aeruginosa, and several species of Mycobaterium and Burkholera colonize in the lung airways, neutrophils are continuously drawn to the site and cause a persistent inflammatory response [7]. The severity of airway inflammation varies widely even among patients who are homozygous for the most common mutation in CFTR, DF508 [8]. The underlying mechanisms that cause neutrophils to lose their function for pathogen clearance are not well understood; therefore, effective pharmacological approaches are lacking.

Despite the fact that CF results from mutations within the CFTR gene, initial studies found a poor association between the genotypes of CFTR and the severity of lung disease [8,9]. However, recently a genome-wide association found a novel candidate gene associated with the severity of CF lung disease-interferon-related development regulator-1 (IFRD1) [10]. Interestingly, higher protein levels of IFRD1 were expressed in peripheral blood neutrophils in patients with $\mathrm{CF}$ compared to those in healthy or non-CF control subjects [10]. This suggests that the upregulation of IFRD1 expression may be involved during the neutrophil's terminal differentiation steps where it acts as a transcriptional co-regulator through its interaction with a histone deacetylase (HDAC) [10]. In neutrophils, the interaction of IFRD with $\mathrm{HDAC} 1$ modulates the transcriptional activity of $\mathrm{NF} \kappa \mathrm{B}$ p65. Loss of IFRD1 reduces the DNA binding activity of NFkB, whereas the inhibition of HDAC1 leads to the loss of co-repression [11]. This clearly implicates the importance of the interaction of IRFD1 and HDAC1 in regulating the key inflammatory pathways through NFkB activation. IFRD1-deficient mice showed no alteration in neutrophil counts, morphology, or the differentiation markers CD11b and Gr-1, but they did exhibit decreased NF- $\kappa$ B p65 transactivation and significant impairment of oxidative burst, bacterial killing, and the production of tumor necrosis factor (TNF) $\alpha$, chemokine KC, and leukotriene B4 [10]. These observations suggest that IFRD1 acts not only to modify genes but also to regulate a component of the inflammatory function in neutrophils in CF lung disease. More recently, Blanchard and colleagues found decreased IFRD1 protein and increased IFRD1 mRNA expression levels in CF airway epithelial cells, compared with control cells [12]. This observation suggests that IFRD1 may also regulate inflammation through airway epithelial cell expression that may be differentially regulated at the protein and mRNA levels.

IFRD1 expression levels showed a positive association with reactive oxygen species (ROS)/oxidative burst [13]. Interestingly, in patients with CF, IFRD1 protein expression levels in neutrophils were lower in the airway fluids than in the peripheral blood [13]. The sputum supernatant from CF patients decreased intracellular IFRD1 protein expression in neutrophils [13]. The CF airway fluids contain abundant amounts of CXCL8 (interleukin 8 [IL-8]) and CXCL2 [14], and these cytokines mimicked the effect of CF sputum supernatants and significantly downregulated IFRD1 protein expression in neutrophils from healthy controls [13].

Chemokines, CXCL8, and CXCL2 recruit and activate neutrophils through seven transmembrane G-protein-coupled receptors [15]. The chemokine receptors, CXCR1 (IL-8RA) and CXCR2 (IL-8RB), are highly expressed on the neutrophil surface; however, the two receptors have different ligand binding affinities. CXCR1 binds with high affinity to IL-8, whereas CXCR2 binds with high affinity to all CXC chemokines [16-18]. CXCL8 and its receptor, CXCR1, play essential roles in the pathogenesis of CF lung disease. CXCR1 mediates antibacterial host defense in CF airways [19]. However, the reduced IFRD1 expression could be mediated through a CXCR2-dependent pathway (CXCL8-/ CXCL2-induced effects) [13]. Modulating the effect of CXCL8/ CXCL2 can be a potential pharmacological approach to reduce lung inflammation in CF patients.

The genetic analyses showed that three IFRD1 single-nucleotide polymorphisms (SNPs) were associated with longitudinal declines in lung function and modulated IFRD1 expression [13]. These studies demonstrate that IFRD1 expression is (1) systemically upregulated in human CF neutrophils, (2) linked to the production of ROS, and (3) depending on the IFRD1 genotype, modulated by chemokines in CF airway fluids [13]. The IFRD1 blood neutrophil protein levels were significantly higher in patients with CF who were heterozygous for the SNPs rs11771128 and rs4727770 compared with those who were homozygous for these SNPs [13]. Other studies of CF patients have found that the severity of lung disease in children and adolescents was related to $57460 \mathrm{C}>\mathrm{T}$ polymorphism in the IFRD1 gene $[10,11]$. In contrast, the data presented by Marson et al. [20] from CF patient samples indicate that $57460 \mathrm{C}>\mathrm{T}$ polymorphism in the IFRD1 gene is not associated with the severity of the disease. However, the authors explain that differences in how these analyses were done [20] may have caused discrepancies in the results. The authors emphasize the importance of studying polymorphism for a better understanding of clinical variability in patients with the identical CFTR genotypes.

As mentioned previously, the CXCL8 chemokine acting through CXCR2 plays a role in IFRD1 expression. A recent study analyzed the genomic DNA of CF patients for common variations in CXCR1 and CXCR2 using a SNP tagging approach [21]. CXCR1 SNPs,

*Corresponding author: Rafat Siddiqui, Cellular Biochemistry Laboratory, Methodist Research Institute, Indiana University Health, Indiana University Health Indianapolis, IN 46202, USA, Tel: 317-962-6941; E-mail: Rsiddiqu@iuhealth.org

Received July 26, 2013; Accepted July 29, 2013; Published July 31, 2013

Citation: Siddiqui R (2013) Targeting Lung Inflammation in Cystic Fibrosis. J Mo Genet Med 7: e68. doi:10.4172/1747-0862.1000068

Copyright: (c) 2013 Siddiqui R. This is an open-access article distributed under the terms of the Creative Commons Attribution License, which permits unrestricted use, distribution, and reproduction in any medium, provided the original author and source are credited 
CXCR2 SNPs, and haplotypes were assessed for their association with CF lung disease severity, CXCR1 and CXCR2 expression, and neutrophil effector functions. Four SNPs in CXCR1 and three SNPs in CXCR2 strongly correlated with the lung function of patients with CF. SNPs comprising haplotypes CXCR1_Ha and CXCR2_Ha were in high linkage disequilibrium; patients heterozygous for the CXCR1-2 haplotype cluster (CXCR1-2_Ha) had lower lung function compared to patients with homozygous wild-type alleles. CF patients carrying CXCR1-2_Ha showed (1) decreased CXCR1 combined with increased CXCR2 mRNA and protein expression and (2) disturbed antibacterial effector functions. As suggested by the authors [21], their results may provide another pharmacological approaches for the treatment of $\mathrm{CF}$ lung disease.

In conclusion, IFRD1, HDAC1, NFkB p65, CXCL8/CXCL2, and CXCR1/2 play critical roles in sustained inflammation in the lungs of $\mathrm{CF}$ patients. Regulating the expression and the function of these mediators may provide promising approaches for targeting inflammation in the lungs of CF patients.

\section{References}

1. Armstrong DS, Hook SM, Jamsen KM, Nixon GM, Carzino R, et al. (2005) Lower airway inflammation in infants with cystic fibrosis detected by newborn screening. Pediatr Pulmonol 40: 500-510.

2. Khan TZ, Wagener JS, Bost T, Martinez J, Accurso FJ, et al. (1995) Early pulmonary inflammation in infants with cystic fibrosis. Am J Respir Crit Care Med 151: 1075-1082.

3. Konstan MW, Hilliard KA, Norvell TM, Berger M (1994) Bronchoalveolar lavage findings in cystic fibrosis patients with stable, clinically mild lung disease suggest ongoing infection and inflammation. Am J Respir Crit Care Med 150: 448-454

4. Jesaitis AJ, Franklin MJ, Berglund D, Sasaki M, Lord Cl, et al. (2003) Compromised host defense on Pseudomonas aeruginosa biofilms: characterization of neutrophil and biofilm interactions. J Immunol 171: 43294339 .

5. Morris MR, Doull IJ, Dewitt S, Hallett MB (2005) Reduced iC3b-mediated phagocytotic capacity of pulmonary neutrophils in cystic fibrosis. Clin Exp Immunol 142: 68-75.

6. Rommens JM, lannuzzi MC, Kerem B, Drumm ML, Melmer G et al. (1989) Identification of the cystic fibrosis gene: chromosome walking and jumping. Science 245: 1059-1065

7. Coutinho HD, Falcao-Silva VS, Goncalves GF (2008) Pulmonary bacterial pathogens in cystic fibrosis patients and antibiotic therapy: a tool for the health workers. Int Arch Med 1: 24.

8. Kerem E, Corey M, Kerem BS, Rommens J, Markiewicz D, et al. (1990) The relation between genotype and phenotype in cystic fibrosis--analysis of the most common mutation (delta F508). N Engl J Med 323: 1517-1522.

9. Correlation between genotype and phenotype in patients with cystic fibrosis. The Cystic Fibrosis Genotype-Phenotype Consortium. N Engl J Med 329: 1308-1313.

10. Gu Y, Harley IT, Henderson LB, Aronow BJ, Vietor I, et al. (2009) Identification of IFRD1 as a modifier gene for cystic fibrosis lung disease. Nature 458: 10391042.

11. Ehrnhoefer DE (2009) IFRD1 modulates disease severity in cystic fibrosis through the regulation of neutrophil effector function. Clin Genet 76: 148-149.

12. Blanchard E, Marie S, Riffault L, Bonora M, Tabary O, et al. (2011) Reduced expression of Tis7/IFRD1 protein in murine and human cystic fibrosis airway epithelial cell models homozygous for the F508del-CFTR mutation. Biochem Biophys Res Commun 411: 471-476.

13. Hector A, Kormann M, Kammermeier J, Burdi S, Marcos V, et al. (2013)
Expression and regulation of interferon-related development regulator-1 in cystic fibrosis neutrophils. Am J Respir Cell Mol Biol 48: 71-77.

14. Hartl D, Griese M, Kappler M, Zissel G, Reinhardt D, et al. (2006) Pulmonary $\mathrm{T}(\mathrm{H}) 2$ response in Pseudomonas aeruginosa-infected patients with cystic fibrosis. J Allergy Clin Immunol 117: 204-211.

15. Kobayashi $Y$ (2008) The role of chemokines in neutrophil biology. Front Biosci 13: $2400-2407$.

16. Ahuja SK, Murphy PM (1996) The CXC chemokines growth-regulated oncogene (GRO) alpha, GRObeta, GROgamma, neutrophil-activating peptide-2, and epithelial cell-derived neutrophil-activating peptide-78 are potent agonists for the type $B$, but not the type A, human interleukin-8 receptor. J Biol Chem 271 : 20545-20550.

17. Cerretti DP, Kozlosky CJ, Vanden Bos T, Nelson N, Gearing DP, et al. (1993) Molecular characterization of receptors for human interleukin-8, GRO/ melanoma growth-stimulatory activity and neutrophil activating peptide-2. Mo Immunol 30: 359-367.

18. Lee J, Horuk R, Rice GC, Bennett GL, Camerato T, et al (1992) Characterization of two high affinity human interleukin-8 receptors. The Journal of biological chemistry 267: 16283-16287.

19. Hartl D, Latzin P, Hordijk P, Marcos V, Rudolph C, et al. (2007) Cleavage of CXCR1 on neutrophils disables bacterial killing in cystic fibrosis lung disease. Nature medicine 13: 1423-1430.

20. de Lima Marson F, Bariani Marcelino A, Rezende L, Ribeiro A, Ribeiro J, et al (2013) The IFRD1 (57460C.T polymorphism) Gene: A Negative report in cystic fibrosis clinical severity. J Mol Genet Med.

21. Kormann MS, Hector A, Marcos V, Mays LE, Kappler M, et al. (2012) CXCR1 and CXCR2 haplotypes synergistically modulate cystic fibrosis lung disease. Eur Respir J 39: 1385-1390. 